\title{
Indigenous Knowledge, Education and Ethnic Identity: An Ethnography of an Intercultural Bilingual Education Program in a Mapuche School in Chile Patricio Ortiz
}

\author{
Saarbrücken, Germany: VDM-Verlag, 2009. 220 págs.
}

\author{
Nelson Martinez Berrios \\ Geography Graduate Group, University of California - Davis, U.S.A. \\ Email: nmmartinezberrios@ucdavis.edu
}

Entre los mapuche-lafquenche de las áreas costeras de la Región de la Araucanía, existe una forma de conocimiento vernáculo o kimün, inserto en la lengua mapuche mapudungún y que es formalmente transmitido por un sabio o kimche, "intelectual orgánico" mapuche cuyo rol social es el de ser depositario del kimün. El libro de Patricio Ortíz explora la forma en que ese conocimiento, no codificado, es integrado al sistema escolar por medio de la implementación de una intervención educativa enmarcada en el modelo intercultural. El libro, disponible solo en inglés, es el resultado parcial de una investigación doctoral en la Universidad de Texas en Austin y se estructura en siete capítulos -el primero de introducción y el último de conclusiones-, a través de los cuales el autor establece un "dialogo reflexivo" entre fuentes burocráticas, históricas y la realidad empírica. El libro es rico en descripciones que combinan, en una escritura bien elaborada, la experiencia etnográfica del autor con fuentes escritas y orales, lo que permite al lector no solo adentrarse en el paisaje cultural de un grupo humano, sino que ante todo comprender la complejidad de la vida social en una comunidad indígena del siglo XXI.

Mediante la aplicación del método etnográfico, enfocado en un Programa de Educación Intercultural Bilingüe (PEIB) en una escuela básica de la localidad de Piedra Alta en el Área de Desarrollo Indígena (ADI) del Lago Budi, IX Región de La Araucanía, el área con mayor concentración de población mapuche de Chile, el autor busca determinar ¿cuáles son las implicaciones para un efectivo aprendizaje cuando un PEIB incorpora a la práctica docente a la figura del kimche? Con el propósito de responder esta pregunta de investigación, el autor formula cuatro sub-preguntas: 1) ¿Cuáles son las bases de la epistemología y pedagogía mapuche en la construcción del conocimiento y cuál es rol de la familia y la comunidad en ese proceso?; 2) ¿Cómo el conocimiento tradicional mapuche es integrado en el currículum, los textos escolares, y en las prácticas docentes?; 3) ¿¿De qué 
forma el kimche produce narrativas contra-hegemónicas que contribuyen a la reconstrucción de la sociedad mapuche tradicional?; y 4) ¿Cómo los propios estudiantes construyen su identidad mapuche en los espacios de la estructura y agencia de la escuela, y cómo el proceso de apropiación-adaptación, negociación y resistencia toma lugar en medio de cambiantes alianzas y presiones asimilacionistas de la cultura dominante?

El libro es informado por un rango amplio de teorías provenientes de las ciencias sociales, entre las que se incluye: estudios culturales, estudios sobre hegemonía cultural, teoría crítica en educación, teoría post-estructural, y teoría post-colonial. Metodológicamente, se enmarca en lo que el autor define como "un proceso crítico y reflexivo tanto en lo metodológico como en la recolección de datos”, lo que implica un proceso de revisión permanente de la interacción entre el observador y lo observado. Los datos fueron recogidos en observaciones de campo realizadas entre 2002 y 2004 en el área de estudio antes indicada, mediante técnicas de observación participante, entrevistas y conversaciones con informantes clave y por medio de conversaciones informales obtenidas tras el establecimiento de "relaciones colaborativas y amigables”.

Entre los principales resultados del libro destaca el hecho que, desde su implementación a mediados de los 1990, los PEIB han sido objeto de múltiples cuestionamientos provenientes de sectores mapuche y nomapuche. Pese a estos cuestionamientos, el PEIB de Piedra Alta se ha mantenido vigente y es visto con entusiasmo por los encargados de su implementación, aun cuando se reconoce su inestabilidad. En un contexto ambivalente de aceptación y rechazo, la incorporación y validación del kimün y el mapudungún ha tenido un positivo impacto en los jóvenes mapuche y ha mejorado considerablemente su autoestima fortaleciendo de paso la formación de su identidad. Asimismo, el kimün cuando es enseñado por los propios kimche, abre una ventana para el desarrollo de una contra narrativa oral al conocimiento eurocéntrico oficial, creando un "tercer espacio" híbrido y negociado de aprendizaje culturalmente más relevante para los estudiantes. En consecuencia, esta práctica instruccional posibilitaría una forma más fluida en la construcción de identidad. Aún más, el kimün cuando es transmitido por los kimche desencadena un proceso positivo de validación y reafirmación de la identidad mapuche, toda vez que al reforzarse las prácticas sociales aprendidas en el hogar y en la propia comunidad, los estudiantes desarrollan una conciencia más crítica de su pasado indígena, lo que a su vez les permite construir una identidad más hibrida y menos conflictiva en un contexto en el cual deben relacionarse simultáneamente con la realidad chilena, global y mapuche, con las contradicciones que ello provoca. Por último, la enseñanza del mapudungún en la escuela básica de Piedra Alta contribuye a que el proceso instruccional sea más significativo para los estudiantes, quienes pese a las dificultades propias de vivir en un contexto rural, en una comunidad mapuche y en un área de alta concentración de población indígena, pueden conectarse mejor desde su lógica al cambiante mundo en el que viven, lo cual podría impactar positivamente en la sustentabilidad a largo plazo del programa. 
El libro concluye formulando una serie de recomendaciones dirigidas al Estado y a las élites e intelectuales mapuche: a) al Estado, le recomienda dar más consideración a los PEIB y muy particularmente dar mayor reconocimiento a los kimche, quienes en su calidad de intelectuales mapuche poseen una reconocida función social en la transmisión de la cultura. Por lo tanto, al ser integrados al proceso educativo como instructores, estarían en mejor posición de vincular el conocimiento ancestral con la comunidad y con la escuela; b) a las élites e intelectuales mapuche le recomienda observar con mayor atención los PEIB, a fin de despejar las dudas que se ciernen sobre su efectividad, en particular sugiere aprender de la experiencia de países como Nueva Zelanda donde se han implementado con éxito programas similares. El mensaje aquí es que, para ser exitosos, los programas deben ser apoyados por la propia comunidad y la dirigencia mapuche de manera más activa, situación que no ocurre en la actualidad. Por último, sugiere desvincular de la agenda política los asuntos educacionales, toda vez que la demanda urgente por autonomía política y control territorial no son asuntos que se resolverán pronto. En cambio, la solución educativa es más cercana y viable comparada con los otros temas de la agenda, aun cuando se reconoce su urgencia. Dicho de otro modo, los asuntos educativos deberían independizarse de la agenda de reivindicaciones y ser vistos desde un punto de vista estratégico.

El libro responde razonablemente bien a sus preguntas de investigación, mediante la aplicación de un método válido y una prosa convincente. Sin perjuicio de lo anterior, hay algunos temas que bien vale la pena examinar en mayor detalle, tres de los cuales se discuten aquí.

Primero, los son depositarios de una forma de conocimiento tradicional o kimün que, a diferencia de otras formas de conocimiento más específico ejecutadas por otros agentes culturales, como la conducta ceremonial hacia la naturaleza, la cosmovisión o las prácticas de sanación, involucran un tipo de saber esencial para la transmisión del protocolo mapuche para ser persona. En ese sentido, sus alcances trascienden lo meramente instruccional. En tal capacidad, los kimche son o deberían ser reconocidos en las estructuras tradicionales mapuche como portadores de un rol equivalente, aunque distinto, al detentado por figuras como el lonko, la machi y el ngenpin. Solo de esta forma su rol como “intelectuales orgánicos”, según los llama el autor, tendría sentido, puesto que estarían actuando como difusores de la etnicidad, entendida aquí como ideología dominante. Pero en la realidad lo que ocurre es que el sistema educacional chileno es un vehículo de transmisión ideológica. Por lo tanto el kimche, devenido ahora en asesor intercultural de un PEIB, antes que un intelectual mapuche, sería un intelectual orgánico del mismo sistema de dominación que los oprime, una especie de "indio permitido" parafraseando a Hale. Por otra parte, si aceptamos la tesis de una construcción más híbrida, ¿cuál sería el rol de los intelectuales mapuche que operan fuera de las estructuras tradicionales en la construcción de etnicidad o de identidades múltiples, por ejemplo de artistas, historiadores, poetas que han logrado posicionarse en distintas esferas de la sociedad? Hubiera sido interesante plantearse estas cuestio- 
nes a modo de discusión, toda vez que están en la bases de antiguas y nuevas disputas sobre la educación como reproductora del poder simbólico de la cultura dominante.

Segundo, el autor es optimista sobre las posibilidades de los PEIB, basándose en el reconocimiento, aunque no en el examen, de casos exitosos como el de los maoríes en Nueva Zelanda y sugiere que en la Araucanía se adopten medidas para reforzar estas iniciativas. Pese a la evidencia de éxito en otras realidades, en Chile pareciera que las élites intelectuales y líderes del movimiento por mayor autonomía no han considerado el carácter estratégico de estos programas en el avance de la misma causa mapuche, más aun cuando -como apunta el autor- la solución a los problemas territoriales parece no estar cercana. Si bien, la propuesta merece consideración, hubiera sido útil enmarcar esa discusión en términos teóricos, como por ejemplo el de las tecnologías de gubernamentalidad que masivamente se están aplicando en el ADI de Lago Budi y que incluyen aunque no restringido a: ordenamientos territoriales, programas de etnoturismo, salud intercultural, entre otras intervenciones que no solo construyen a los sujetos sobre los que actúan sino que también establecen las reglas de conducta que deben seguir. En consecuencia, no es la exclusión el problema sino que la excesiva sujeción, pues de eso se trata ser sujeto antes que persona. Es por ello que hubiera sido más productivo investigar ¿por qué, probablemente también desde posiciones estratégicas, las élites mapuche no han considerado a la educación intercultural como reivindicación y si es que lo han hecho, por qué se oponen a la implementación de los PEIB?

Tercero, la noción de lo ancestral está dispersa en el libro en diferentes contextos, aunque todos, al menos aparentemente, referirían a la dimensión temporal intrínseca a la sociedad mapuche contemporánea que la conectaría con la sociedad mapuche de otras épocas. Por ejemplo, el autor usa lo ancestral indistintamente como un atributo para calificar distintas dimensiones de la existencia cultural y material de los mapuche que se expresan en 'área ancestral', 'comunidad ancestral', 'conocimiento ancestral', 'lenguaje ancestral', 'territorios y tierras ancestrales', 'tiempo ancestral'. La recurrencia del concepto estaría indicando entonces el reconocimiento de una categoría analítica, que sin embargo no está explicitada en sus características, limitaciones y potencialidades. En el plan de libro, ninguno de estos aspectos es considerado, así como tampoco se aprecia una definición que permita entender el uso de lo ancestral como una categoría de análisis. La ausencia de esclarecimiento sobre el significado de esta noción estaría indicando que se toma como algo meramente sobrentendido, es decir como un atributo per se. No es el objeto discutir las categorías analíticas escogidas por el autor para soportar sus argumentos, que por lo demás es un privilegio del que dispone. Ahora bien, es precisamente en función de la insistencia en el uso del concepto que el lector legítimamente puede preguntarse ¿qué es en definitiva lo ancestral? La pregunta no es insustancial, principalmente porque es el carácter ancestral de la sociedad mapuche, al igual que sus mecanismos de reproducción, lo que está en permanente cuestionamiento, mucho del cual proviene de las ciencias sociales. Conse- 
cuentemente, dado que el kimün es un factor de continuidad y contribuye a la reproducción de la cultura, una mayor clarificación conceptual habría servido para despejar dudas.

En el balance final, el libro ilustra con buenos argumentos el potencial que la implementación de un PEIB tiene: para la construcción de una identidad hibrida; para la entrega de contenidos educacionales pertinentes; y para mejorar la autoestima de los estudiantes. Pero sobre todo, ilustra las profundas contradicciones que su aplicación desata entre los habitantes de la comunidad de Piedra Alta, demostrando finalmente que las batallas por la educación son siempre batallas ideológicas. Por todas esas razones, es un libro que bien merece la pena ser leído no solo por las cuestiones de las que trata, sino también por las discusiones a las que podría dar lugar, en cualquier caso hace una importante contribución al campo de los estudios interculturales. 